\title{
A New Control Strategy for Hybrid Energy Storage System with a Bidirectional DC-DC Converter for EV application
}

\author{
Venkatesh Kama $^{1}$, S.K Biradar ${ }^{2}$ \\ Electrical Engineering Department, AISSMS COE, Pune, Maharashtra, India ${ }^{1}$ \\ Assistant Professor, Electrical Engineering Department, AISSMS COE, Pune, Maharashtra, India ${ }^{2}$
}

\begin{abstract}
With the emerging technologies in the field of Energy Storage System Development, the interest for the development of Electric Vehicle (EV's) is growing for future road transportation.In this paper the Battery plus Ultracapacitor (UC) Hybrid Energy Storage System(HESS)with an energy management control strategy is proposed. The proposed control strategy optimizes the energy consumption, improves vehicle performance and prolongs the battery lifetime for different vehicle Drive cycles. The proposed HESS topology incorporates the bidirectional DC-DC converter and a complimentary switch pair for interconnection of energy sources and interconnection with vehicle traction drive. The proposed HESS interconnected with BLDC motor and the control strategy is implemented for the acceleration and braking conditions of the vehicle. The DC- DC converter is of small size and itis used for sharing the energy between Battery and Ultracapacitor. It also balances the energy levels of the two sources based on the vehicle drive cycles. And the complimentary switch pair swaps the vehicle load between the two sources based on the vehicle driving condition for optimum energy consumption. The Ultracapacitor contributes to the rapid energy recovery associated with regenerative braking and rapid energy consumption associated with vehicle acceleration. This power system allows the acceleration and deceleration of the vehicle with minimal loss of energy and minimizes the stress on the main batteries by reducing high power demands away from the batteries. The objective of the control strategy developed is to provide uninterrupted and adequate power from HESS to the vehicle motor drive unit for all drive cycles of vehicle. The control logic considers the Battery Voltage, Ultracapacitor Voltage and vehicle speed in order to provide a smooth control, reliable and efficient energy sharing between HESS and vehicle motor drive unit. The Battery SOC and open circuit voltage $(\mathrm{OCV})$ are important parameters for ascertaining battery life because fully charged batteries do not accept any current and hence, under this condition, the Ultracapacitor should be available discharged (that means no more than 15-20\% of its full capacity) to store the energy generated due to regenerative braking at high speeds. By contrast, if the battery state of charge is poor, the ultracapacitor should be available fully charged (that means more than $90 \%$ of its full capacity) to power the traction motor for sudden acceleration. To achieve this requirement both the sources are interconnected through a bidirectional DC-DC Converter which is controlled by the speed of the vehicle.And thus the UC voltage is maintained at required level based on the vehicle speed by sharing the energy between Battery and UC for different drive cycles of the vehicle.
\end{abstract}

Keywords: Bidirectional DC-DC Converter, BLDC Motor, Ultracapacitor, Battery and Hybrid Energy Storage System (HESS).

\section{INTRODUCTION}

An efficient Energy Storage System (ESS) is of prime The essential requirements of the ESS for anefficient EV's importance in Electric Vehicle (EV) systems.The ESS for are high energy and power density, excellent cycle EV shouldbe controllableto regulate the energy flow life,good reliability and high safety. The limitations of within the vehicle with the aim of using energy as battery electric vehiclesfor the main requirements like economically as possible and to charge batteries as accelerating, climbing and braking conditions of the convenient and efficient as possible for vehicle drive vehicle can be overcome by developing an ESS with high cycles.

rate and efficient charge and discharge capability.

An ESS with Battery alone as energy sourceis not efficient as the power density of battery is much smaller so a large number of batteries must be used to assure a certain level of power performance. However mountinga large number of batteries results in increased vehicle weight and cost [1].

By establishing Hybrid energy storage system (HESS)by combining two or more types of storage components with complementary features the power and energy densities achieved as required.The Battery plus ultra capacitorHESS can fulfil power and energy requirements of vehicle. Ultra capacitor stores energy in an electric field like double 
Vol. 5, Issue 2, February 2017

layer capacitorso the charge and discharge characteristics are much faster than batteries as there is no energy conversion. They can also survive up to a million charge and discharge cycles, whereas battery lifetime is restricted by degrading chemicals. Ultracapacitor has little Low Equivalent Series Resistance (ESR). When compared to Batteries, Ultracapacitor has a low internal resistancehence it provides high power density capability. They are also significantly lighter than batteries, and generally don't contain harmful chemicals or toxic metals [2].

Hybrid Energy Storage Systems (HESS), which includes both batteries and ultracapacitors (UCs), have been proposed in many different topologies in the literature for hybrid electric vehicle (HEV) and electric vehicle (EV) applications[4]. Employing UCs in HESS relieves the high-energy density battery unit from the peak power transfer stress due to their higher specific power and efficiency [3].This extends the battery life span and greatly reduces the required battery size. The topologies of HESS have been studied over the past fewyears. A review of the most widely used conventional HESS topologies are discussed in [4].

As shown in Fig 1.1 Conventional ESS topology, inconventional method of interfacing the UC unit, a bidirectional $\mathrm{dc}-\mathrm{dc}$ converter is used to control the power flow in/out of the UC in line with changing power requirement of load. Therefore, despite the wide variations of the UC terminal voltage, the voltage across the motor drive dc link remains constant. The dc-dc interfacing converter introduces considerable switching and conduction power losses. It also causes some stability issues, particularly at high inrush currents [5]. Moreover, itadds cost and weight to the system, particularly due to its large inductor rated for the peak power transfer.

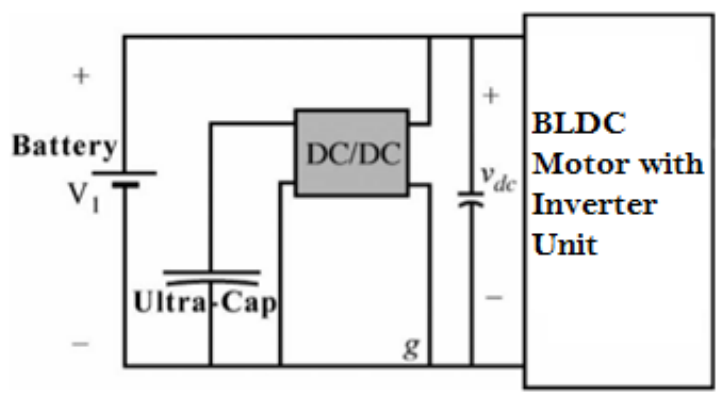

Fig 1.1Conventional ESS topology

In this paper, a new approach is introduced for interconnecting theEnergy sources in HESS and to control the flow of energy from HESS and Vehicle Traction Drive.In the proposed HESS there is no intermediate DCDC converter used between HESS and Traction Drive. The proposed HESS for EV is divided into two sub systems. In scheme I UC unit is directly interfaced with the motor drive dc link as shown in Fig. 1.2: scheme I, there is no intermediate DC-DC converter is needed andtherefore,no extra losses are introduced. The UC is utilized onlyduring the peak power surges such as starting, braking and acceleration. And for the normal operation, power is drawn from the Battery by using a complementary switch pairs between the UC bank and Battery and the whole system is connected to the motor drive. The swapping between the two sources can be done by controlling the complimentary switch pair as shown in Fig. 2.1 (b), (c) and (d) (scheme I). The resulting wide variation of dc-link voltage i.e. Vdc is handily resolved by the inverter modulation of motor drive unit.

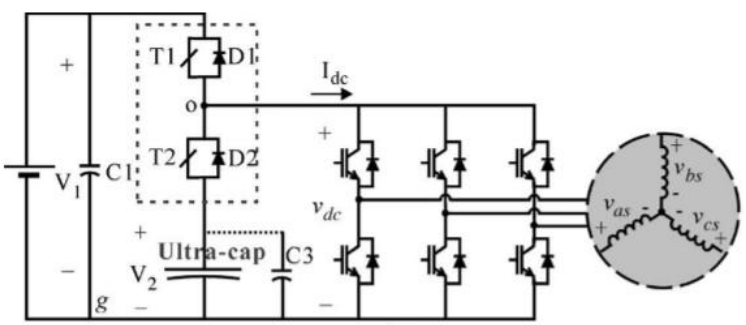

Fig 1.2 Scheme I topology

In order to make ESS more reliable and efficient, a DCDC converter is used for interfacing the Battery with UC as shown in Fig 1.3 Scheme II topology. This Bidirectional DC-DC converter charges battery from UC when the charge on UC bank is very high, normally this happens when brakes are applied frequently. And therefore, the complete coverage for peak power demands by the UC leads to a major reduction in the battery size.

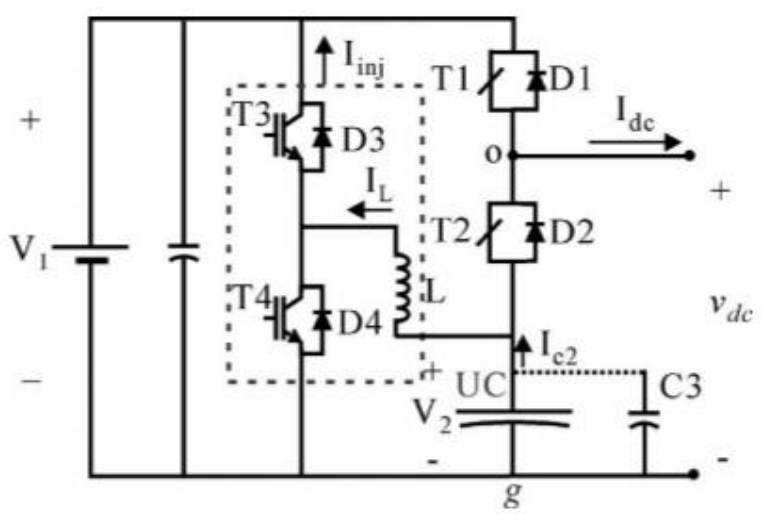

Fig 1.3 Scheme II topology

For heavily hybridized HEVs or pure EVs, where a large ESS is required, an alternative scheme (ESS scheme II) is proposed. An additional hardware is used and increased UC sizing, it inherits the good features of scheme I, such as high efficiency via direct UC interface; it is also possible to achieve the regular $\mathrm{HEV} / \mathrm{EV}$ peak power demand with only UC source due to increased size; therefore, the internal combustion engine (ICE) and batteriescan supply only for the baseline power demands. In a heavily hybridized HEV, the ICE is small, and the electric propulsion subsystem power share is considerable [6]. Therefore, the complete coverage for peak power 
demands by the UC leadsto a major reduction in the battery size, which justices the increased UC sizing and cost [7].

\section{OPERATION OF PROPOSED SYSTEM}

The proposed HESS is divided in two schemes based on the HESS topologies and vehicle requirement. In the first scheme there exists two controls one is for the swapping the sources based on the vehicle driving modes like Starting, Acceleration and Braking which is simple and more suitable for HEV's. And the scheme includes a bidirectional DC-DC converter which is connected between $\mathrm{UC}$ and battery for allowing the energy transfer between two sources based on the speed of the vehicle.

\section{A. Operation of Scheme I}

As shown in the scheme I the vehicle traction load can be distributedbetween two sources by using the complimentary switch pairs. These switches can be of solid state (power electronic) switches or electro mechanical switches. Power electronic switches are more reliable and can be controlled athigh switching frequencies. Electromechanical switches are not so reliable for high switched frequencies and have loss to due to high contact resistance compared to solid state switches.

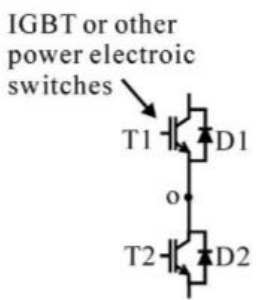

(a)

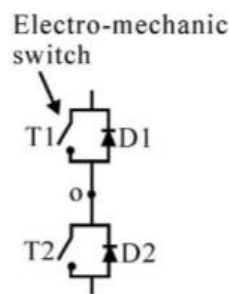

(b)

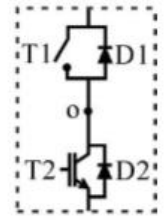

(c)
Fig 2.1 complimentary switch pair for swapping sources

The proposed scheme I HESS topology is an efficiencyimproving scheme features a simple and costeffectivetopology as there is no dc-dc converter for interfacing UC.Either the battery or UC source is connected across the motor drive dc link via the complimentary switch pair ( $\mathrm{T} 1$ and $\mathrm{T} 2$ ), as shown in Figure 1.2: Scheme I topology. An electrolytic capacitor $\mathrm{C} 1$ is connected in parallel with the battery as the source for the motor drive dc-link current pulse width-modulation (PWM) pulses. The electrolytic capacitor $\mathrm{C} 3$ can be connected in parallel as shown depending on internal resistance of UC.

The lower limit of the UC voltage V2 is set at $1 / 3$ of its upper limit (battery voltage V1); therefore, the discharge depth (DOD) is $8 / 9$ of its full capacity. When T1 is on and $\mathrm{T} 2$ is off, thepoint " $\mathrm{o}$ " is clamped to $\mathrm{V} 1$, and D2 is reverse biased; the UC is then isolated, and the battery becomestheonly source for the motor drive. When T2 is on
andT1 is off, the dc source is swapped to the UC, and D1 is reversed biased, leavingthe battery bank isolated from charging/discharging current Idc. When the peak power surge occurs during braking and acceleration, the UC source can be swapped in for higher efficiency until the peak power cycle ends or the UC SOC reaches its upper/lower limits.

This proposed ESS topology has a fault tolerance feature in that the UC is protected against overcharging when the controller malfunctions because of the discharge path via the anti parallel diodes D1 and D2, which keeps V2 below the battery voltage V1. Also, during dead time when T1 and $\mathrm{T} 2$ are both off, Idc still has the path via either D1-C1 (negative Idc) or D2-UC (positive Idc); thus, no highvoltage spike is induced.

\section{B. Operation of Scheme II}

The proposed scheme II HESS topology has three operation modes for peak power demands.

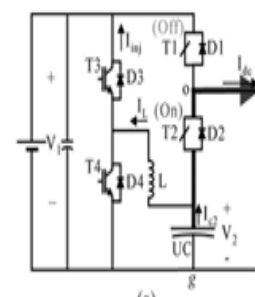

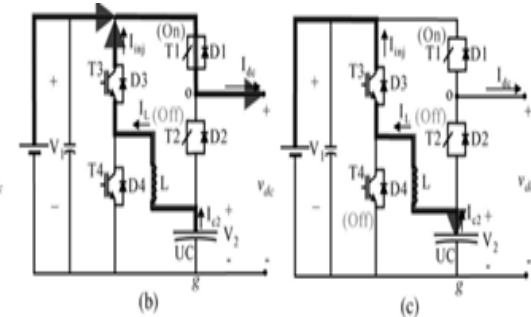

(c)
Fig 2.2 Scheme II HESS operating modes

Mode I: For braking and acceleration in the urban speed range this mode of operation is used. Therein, the $\mathrm{dc}-\mathrm{dc}$ converter and the battery are bypassed and the UC becomes the direct power source of the motor drive as shown in Figure 2.2 (a).

Mode II: For high vehicle torque requirements the majority of the power demands are transferred from/to the UC by controlling the magnitude of the inductor current (within the $\mathrm{dc}-\mathrm{dc}$ converter) by buck-boost modes of operation. In this mode both the sources of HESS will supply energy simultaneously and the majority of power demand is supplied from UC and rest is supplied by battery as shown in Figure 2.2 (b).

ModeIII: For high vehicle starting torque requirements and during idle period between braking and subsequent acceleration cycle the UC should be fully charged to from the battery in parking and when UC charge reduced to $1 / 3$ of its total charge so in this mode UC charged from battery as shown in Figure 2.2(c).

\section{CONTROL STRATEGY OF PROPOSED SYSTEM}

For the proposed HESS there are two control strategies first one is for controlling the motor speed and the second 
Vol. 5, Issue 2, February 2017

one is for transferring energy between battery and UC. The schematic circuit of the proposed system shown in Fig 3.1 is HESS with BLDC Motor Drive Unit is modelled in Matalab Simulink.

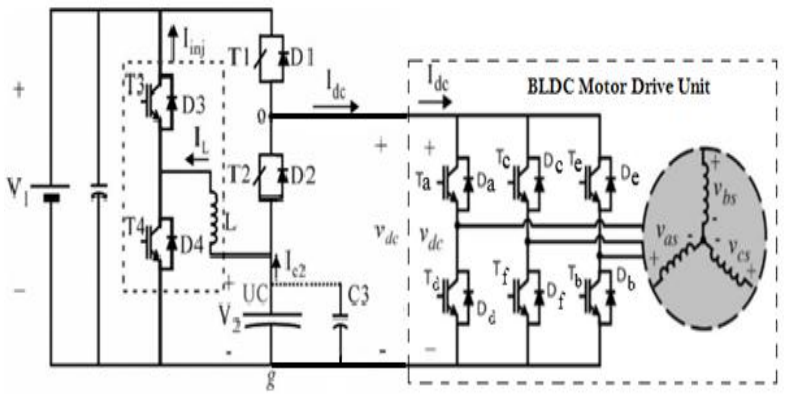

Fig 3.1 HESS with BLDC Motor Drive Unit

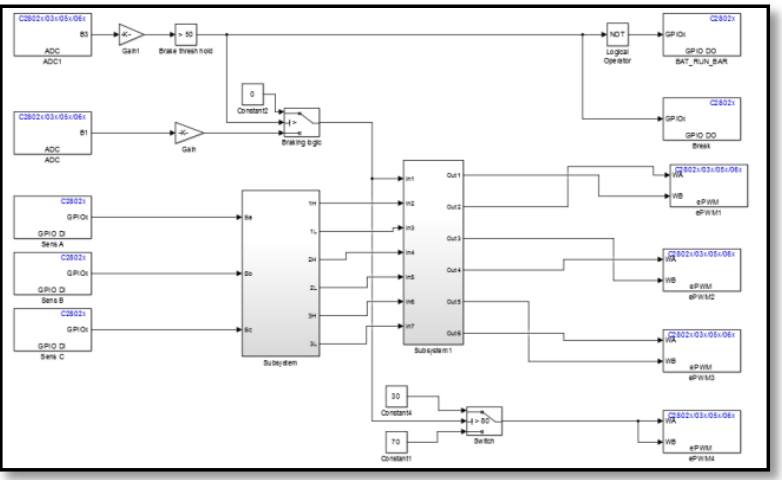

Fig 3.2 Control logic of HESS in Matlab Simulink

$>\mathrm{ADC}, \mathrm{ADC} 1-$ Used to increase (acceleration) or decrease (deceleration) of speed.

> Braking logic-Used to generate ePWM1, 2\&3 as per the Vehicle speed control which control the Ta to Tf.

$>$ Switch-Used to transfer the energy among the sources and capture regenerated energy.

\section{A. Motor Speed control:}

The proposed HESS includes the "BLDC motor with power electronic converter" as traction motor drive. The BLDC motor has the merits of simple structure, high efficiency, electronic commutating device, high starting torque, noiseless operation and high speed range, etc. Hence, the brushless DC motor has been widely used in EVs [8].

The commutation of BLDC motor is a six-step process. All six sides of the 3-phase Inverter are turned on and off to create the six flow vectors. These vectors make the BLDC motor point $60^{\circ}$ to the next position for each step. The six steps cause a full revolution $\left(6\right.$ steps $\times 60^{\circ}=$ $360^{\circ}$ ). The Hall effect sensor is used for sensing the rotor position which outputs a logic level based on the detection of a magnetic field [9].

With Hall Effect sensors, a simple BLDC control system needs only 9 pins from a microcontroller; sixpins tocontrol the 6 sides of 3 phase inverter and three pins to sense the Hall Effect switches.

A table in the memory is enough for the processor to determine the next commutation with the six-step process and the Hall Effect sensor outputs. Table 3.1 shows an example of this concept.

Table 3.1 An example of six-step commutation process with Hall Effect sensor outputs concept.

\begin{tabular}{|l|l|l|l|l|l|}
\hline $\begin{array}{l}\text { Hall } \\
\text { Senso } \\
\text { r A }\end{array}$ & $\begin{array}{l}\text { Hall } \\
\text { Sensor } \\
\text { B }\end{array}$ & $\begin{array}{l}\text { Hall } \\
\text { Senso } \\
\text { r C }\end{array}$ & $\begin{array}{l}\text { Phase } \\
\text { A }\end{array}$ & $\begin{array}{l}\text { Phase } \\
\text { B }\end{array}$ & $\begin{array}{l}\text { Phase } \\
\text { C }\end{array}$ \\
\hline 1 & 0 & 0 & $-\mathrm{V}_{\mathrm{DCB}}$ & $+\mathrm{V}_{\mathrm{DCB}}$ & $\mathrm{NC}$ \\
\hline 1 & 0 & 1 & $\mathrm{NC}$ & $+\mathrm{V}_{\mathrm{DCB}}$ & $-\mathrm{V}_{\mathrm{DCB}}$ \\
\hline 0 & 0 & 1 & $+\mathrm{V}_{\mathrm{DCB}}$ & $\mathrm{NC}$ & $-\mathrm{V}_{\mathrm{DCB}}$ \\
\hline 0 & 1 & 1 & $+\mathrm{V}_{\mathrm{DCB}}$ & $-\mathrm{V}_{\mathrm{DCB}}$ & $\mathrm{NC}$ \\
\hline 0 & 1 & 0 & $\mathrm{NC}$ & $-\mathrm{V}_{\mathrm{DCB}}$ & $+\mathrm{V}_{\mathrm{DCB}}$ \\
\hline 1 & 1 & 0 & $-\mathrm{V}_{\mathrm{DCB}}$ & $\mathrm{NC}$ & $+\mathrm{V}_{\mathrm{DCB}}$ \\
\hline
\end{tabular}

The proposed control logic is as shown in Fig 3.2 Control logic of HESS in Matlab simulink. In which the output signals generated by Hall Effect Sensors A, B and C are converted into six steps using the logic gates (complimentary function). These six steps are controlled by Braking logic which resembles to the actual braking of the vehicle. This controls the commutation of the BLDC motor drive inverter switches by PWM signals.

The acceleration and brake control inputs ADC and ADC1 are used to control by motor speed as applied by using accelerator pedal. Thus ePWM1, ePWM2 and ePWM3 signals are generated with the above control signals and these PWM signals control the switching of power electronic switches which generates the controlled stator phase voltage.

The Speed of BLDC motor is directly proportional to the voltage applied to the stator. While commutation keeps the magnetic flux vector rotating, so the speed at which the actual rotor is forced to the next position is determined by the strength of this magnetic force created. As discussed above by using PWM signals at a higher frequency than the commutations, the amount of voltage applied to the stator winding can be easily controlled; therefore the speed of the motor can be controlled.Torque isalso controlled by reducingvoltage applied to stator winding when the torque load of the motor is higher than indicated.

B. Transferring energy between Battery and Ultra Capacitor:

In the above circuit T3, D3, T4, D4 and L are the part of DC-DC converter which is connected between battery and ultra capacitor. As shown in the circuit the battery is connected on the boost side of the converter and UC is connected on the buck side of the converter. The converter 
switches T3 and T4 are controlled based on the vehicle speed. When the speed of the vehicle is high converter operates in boost mode and UC charges the battery.

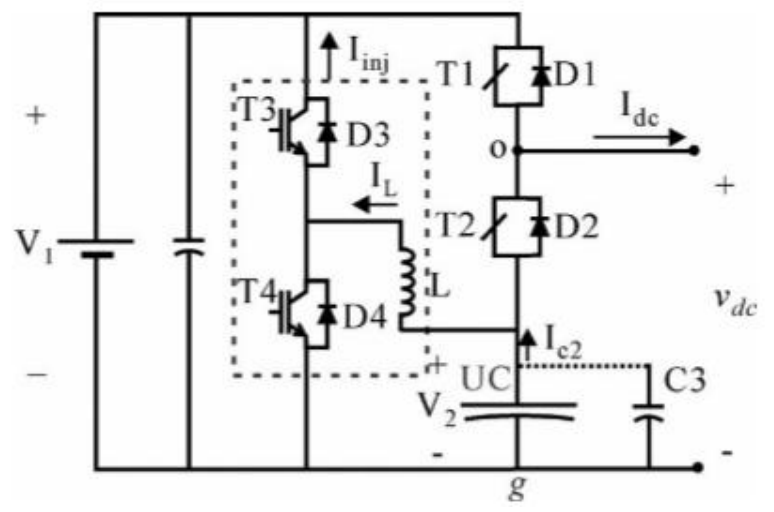

Fig3.3 Control circuit of HESS in Matlab simulink

When the voltage of the UC reduces the pre-set valuethe converter operates in buck mode and battery charges the Ultracapacitor to maintain the sufficient charge on UC for future acceleration.

In the Fig 3.2 Control circuit of HESS in MatlabSimulink, the ePWM4 is used to control the switches T3 and T4,as per given control logic when the speed is above $80 \%$ of the maximum speed, the switches $\mathrm{T} 3$ and $\mathrm{T} 4$ are switched at duty ratio of $70 \%$ and the inductor $\mathrm{L}$ get charged from the ultracapacitor. Thus the converter operates in boost mode and transfers the energy from ultracapacitor to battery so that ultracapacitor charge is reduced to capture the energy in subsequent braking at high vehicle speeds.

For the speeds below the $80 \%$ of maximum speed the switches T3 and T4 are switched at duty ratio of 30\% and the inductor L get charged from the Battery. The converter operates in buck mode and transfers the energy from battery to ultracapacitor this happens before starting the vehicle and while parking vehicle thus the system will operate in Mode III.

The ultracapacitor can be charged for the voltage below battery voltage if ultracapacitor voltage increases than battery voltage then the diode $\mathrm{D} 2$ will be in forward biased and thus ultracapacitor supplies the vehicle load and system will operate in Mode I.

As per the control logic in the Figure 3.2 Control logic of HESS in Matlabsimulink, when the brake is applied by ADC1 which generates the braking input signal, the commutation of switches $\mathrm{T} 1$ and $\mathrm{T} 2$ controlled.

When the brake threshold value greater than the pre-set value, the switch T1 will get turned off and T2 will get turned on and at the same time speed reference tothe BLDCmotor speed control logic (Subsystem1 in Fig 3.2) will becomes zero which stops the supply to motor and thus the energy generated in the motor windings due to regenerative braking is stored in the ultracapacitor until the brake is applied as ultracapacitor alone connected to BLDC motor.

Before starting the vehicle the Ultracapitor must be fully charged if not it is charged by battery so thatultracapacitor voltage will get equal to Battery voltage in such condition $\mathrm{T} 1$ is turned on as speed less than pre-set value and T2 is turned off and the motor will be supplied from battery as well as ultracapacitor as both the sources are in parallel to the motor drive thus the high starting torque is supplied from both the sources of HESS thus Mode II operation is achieved.

From control logic shown in Fig 3.2 Control logic of HESS in Matlab Simulink, programming logic code can be generated which is used to generate the programme code. This code is stored in LAUNCHXL-F28027 C2000 Piccolo Launch Pad Experimenter Kit and the GPIO pins of this kit are interconnected with BLDC motor Sensors, bidirectional DC-DC converter, BLDC inverter unit and input speed and brake controls. LAUNCHXL-F28027 C2000 Piccolo Launch Pad will provide the supply to BLDC Hall effect sensors and the output of the sensors fed back with these signals the ePWM1 to ePWM3 signals generated to trigger the each side of inverter switches. The input given through $\mathrm{ADC}$ and $\mathrm{ADC} 1$ are analog in nature which are converted into digital and these signals used for Implement all 3 modes of the operation. Apart from the acceleration and braking some other logics can also implemented by using the other leftover pins of LAUNCHXL-F28027 C2000 Piccolo Launch Padwith control logic as required and the enhanced PWM peripheral supports independent/complementary PWM generation, adjustable dead-band generation for leading/trailingedges, latched/cycle-by-cycle tripmechanism. Some of the PWM pins support HRPWM features.

\section{IV.SIMULATION OF THE PROPOSED SYSTEM}

The proposed HESS with BLDC Motor Drive Unit is modelled in MatlabSimulink. It is simulated for the time period of 10 seconds and for the duration of 4 to 6 seconds brake is applied and following result obtained from the simulation. This result shows the Motor speed, Battery and UC voltage and current wave forms.

From the simulation results of the proposed system it is observed that for the time period 4 to 6 seconds (refer Braking Signal from 4 to $6 \mathrm{Sec}$ in Fig 4.1) the motor speed is zero as brake is applied for the same time period the battery current is zero and the battery voltage is constant as the battery is isolated for this braking period to protect the battery from high regenerative current pulses. And for the same time period of 4 to 6 Seconds the Ultracapacitor voltage is suddenly raised as it is getting charged due to the regenerative braking for the time. 

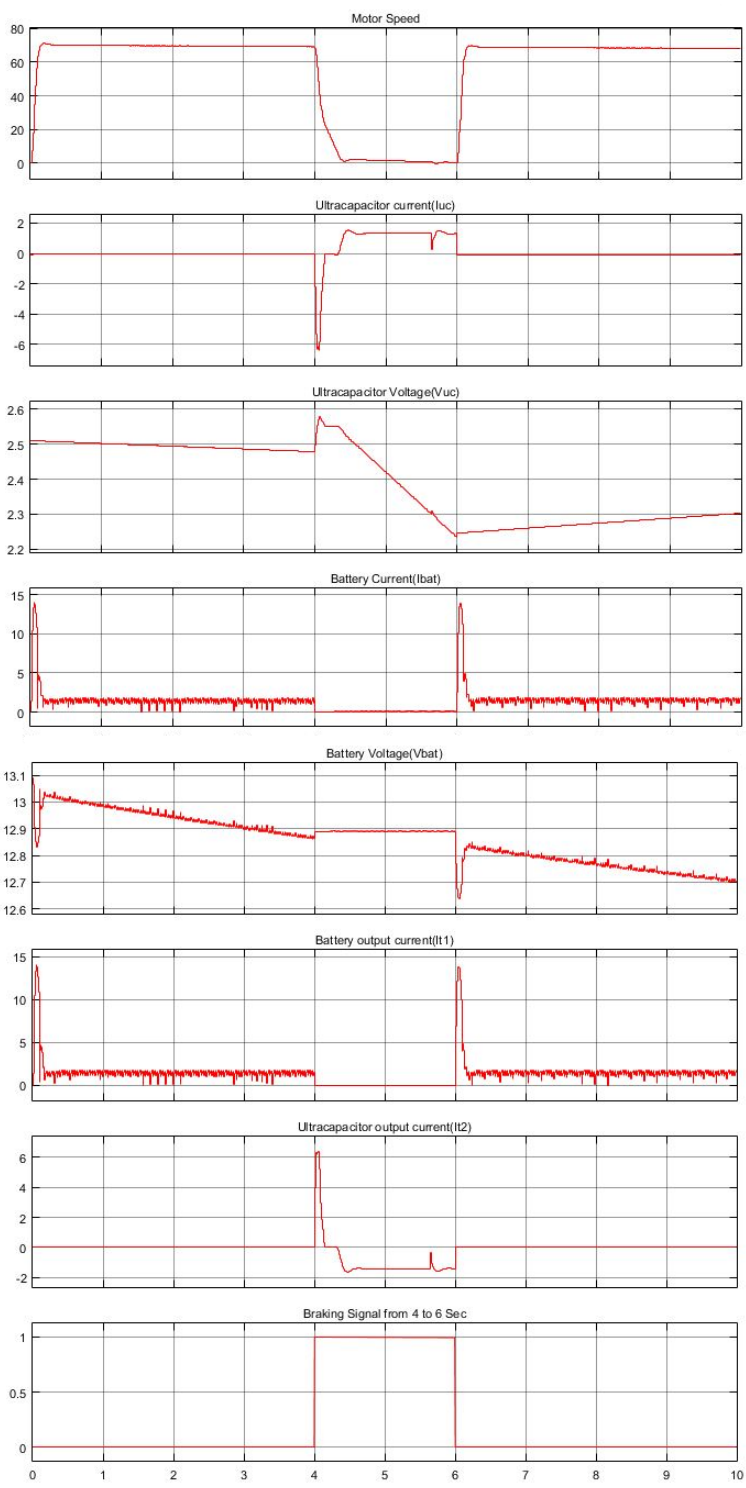

Ime offset

Fig 4.1Motor Speed, Battery and Ultracapacitor Voltage and current, Braking signal

\section{CONCLUSION}

As per the simulation results of the proposed HESS it is observed that the Battery get isolated for the duration of braking and the power generated from the motor due to regenerative braking stored in the ultracapacitor. As the battery doesn't have the good power density to store the regenerated power for the short duration of braking proposed HESS topology with ultracapacitor will shield the battery from this high voltage spikes and the life of the battery cycle of the battery get improved.

\section{ACKNOWLEDGMENT}

I humbly wish to extend my cordial gratitude with profound thanks to S. K. Biradar for his meticulous planning, valuable guidance, constant encouragement, and the invaluable time he spent with me in discussing each aspect of this paper publication.

\section{REFERENCES}

[1] S.K. Biradar, SES College of Engineering Kopargaon, R,A.Patil, BasaveshwarEngg. College, Bagalkot and MaheshwariUllegaddi, S.N.I.J.P.S.N Polytechnic"Energy Storage System in Electric Vehicle" Power Quality'98, 1998, pp. 247-255.

[2] A. Burke, "Ultracapacitors: why, how, and where is the technology", Journal of power sources, vol. 91, pp. 37-50, 2000.

[3] S.Mallika and Dr. R.Saravana Kumar, "Review on UltracapacitorBattery Interface for Energy Management System" International Journal of Engineering and Technology Vol.3 (1), 2011, 37-43.

[4] Jian Cao, Member, IEEE, and Ali Emadi, Senior Member, IEEE, “A New Battery/UltraCapacitor Hybrid Energy Storage System for Electric, Hybrid, and Plug-In Hybrid Electric Vehicles"IEEE transactions on power electronics, vol. 27, no. 1, January 2012.

[5] NassimRizoug, Gilles Feld, RedhaSadoun and Bertrand Barbedette "Hybrid Supply for Automotive Application Using Supercapacitors" Journal of Energy and Power Engineering 6 (2012) 1688-1697.

[6] HarpreetsinghBanvait, Sohel Anwar, Member, ASME, and Yaobin Chen, Member, IEEE“A Rule-Based Energy Management Strategy for Plugin Hybrid Electric Vehicle (PHEV)"2009 American Control Conference Hyatt Regency Riverfront, St. Louis, MO, USA June 10-12, 2009.

[7] Junyi Shen, SerkanDusmez, Student Member, IEEE, and AlirezaKhaligh, Senior Member, IEEE “Optimization of Sizing and Battery Cycle Life in Battery/Ultracapacitor Hybrid Energy Storage Systems for Electric Vehicle Applications"IEEE transactions on industrial informatics, vol. 10, no. 4, November 2014.

[8] Young-kyoun Kim, Se-Hyun Rhyu, and In-Soung Jung, "Parameter Determination of the BLDC Motor considering the Dynamic Equation of Vehicle"XIX International Conference on Electrical Machines - ICEM 2010, Rome.

[9] Eduardo Viramonte, Systems and Applications Engineering, Freescale Technical Support "BLDC Motor Control with Hall Effect Sensors Using the 9S08MP"Document Number: AN4058,Rev. 0, 4/2010, Application Note,Freescale Semiconductor. 